\title{
A Utilização de Perfiladores Acústicos de Corrente por Efeito Doppler na Determinação do Material Particulado em Suspensão na Água: Aplicações
}

\author{
Carlos A. F. Schettini, Alexsandro R. Zaleski \\ Centro de Ciências Tecnológicas, da Terra e do Mar-CTTMar/Universidade do Vale do Itajaí \\ guto@univali.br; arzaleski@gmail.com
}

Recebido: 10/05/05 revisado: 13/09/05 aceito: 29/03/06

\section{RESUMO}

Por meio de três experimentos realizados no estuário do Rio Itajaí-açú foi possível avaliar o desempenho de dois modelos de Perfiladores Acústicos de Corrente por efeito Doppler (PACD) na determinação da concentração de Material Particulado em Suspensão (MPS) na água. O primeiro experimento consistiu no fundeio de um PACD por dois meses ao largo do estuário do Rio Itajaí-açú, próximo a isóbata de 10 metros. A partir dos dados coletados foi possível verificar os padrões de correntes e transporte do MPS nesta região. O segundo experimento consistiu no monitoramento da pluma sedimentar ocasionada por uma draga de extração de areia. Utilizando um PACD com o dispositivo "Bottom Tracking", que o permite funcionar montado a uma embarcação, foi realizado um perfil em direção a uma draga de extração de areia em operação. A partir das informações acústicas coletadas pelo PACD foi possível verificar a pluma sedimentar causada pela draga e a concentração de MPS na mesma. Neste experimento uma limitação deste método ficou evidente. Sob a condição de alta concentração de MPS o PACD não conseguiu obter informação do fundo. No ultimo experimento buscou-se verificar a distribuição do MPS ao longo do estuário do Rio Itajaí-açú sob condição de alta descarga de sólidos em suspensão. Para tal foi realizado um perfil vertical-longitudinal com um PACD e simultaneamente com um turbidimetro de Retro Espalhamento Ótico (REO) para se comparar as medições. Este experimento mostrou uma outra limitação deste método para estimar a concentração de MPS na água, a limitação quanto ao tamanho das partículas em suspensão e a freqüência do PACD utilizado. O PACD 1,5 MHz utilizado neste experimento não foi capaz de visualizar as partículas finas presentes no estuário.

Palavras-chave: Estuário, Sedimentos, Perfilador Acústico de Correntes por efeito Doppler.

\section{INTRODUÇÃO}

A crescente utilização dos Perfiladores Acústicos de Corrente por efeito Doppler (PACD) despertou um grande interesse nas técnicas para se estimar a concentração do Material Particulado em Suspensão (MPS) na água a partir destes equipamentos (Gartner, 2002). A possibilidade de se obter informações de velocidade de corrente e concentração de MPS com um único equipamento já é uma realidade nos dias atuais. Apesar de algumas limitações, que serão mostradas neste trabalho, existem muitas vantagens em se estimar a concentração do MPS na água através das informações acústicas dos PACDs. Uma das principais vantagens é a resolução espacial e temporal obtidas. Os dados obtidos com PACD's fornecem uma excelente visão dos processos de toda a coluna d'água. Por se tratar de um sensor remoto, não existe a necessidade dele ser baixado e suspenso na coluna de água, o que facilita muito sua operação. Outra vantagem é que o Retro Espalhamento Acústico (REA), utilizado para se estimar a concentração de MPS na água, é um subproduto das medições de velocidade, logo é possível se obter informações sobre o MPS sem a necessidade de um sensor extra.

Este trabalho apresenta três experimentos realizados com dois modelos de PACD convencionais no estuário do Rio Itajaí-açú. Ambos os PACDs foram calibrados para as condições de MPS deste estuário com a utilização de um turbidímetro de Retro Espalhamento Ótico (REO) (Zaleski e Schettini, submetido).

\section{AREA DE ESTUDO}

O estuário do Rio Itajaí-açu está localizado no litoral centro-norte do estado de Santa Catarina. Este estuário é um sistema altamente estatificado dominado por processos fluviais. A vazão média do Rio Itajaí-açu é aproximadamente $250 \mathrm{~m}^{3} . \mathrm{s}^{-1}$ na estação fluviométrica de Indaial $(90 \mathrm{~km} \quad$ da 
A Utilização de Perfiladores Acústicos de Corrente por Efeito Döppler na determinação do Material Particulado em Suspensão na Água: Aplicações

desembocadura), contudo apresenta grande variabilidade intra anual, permanecendo baixa $(<$ $\left.150 \mathrm{~m}^{3} . \mathrm{s}^{-1}\right)$ a maior parte do tempo, com picos distribuídos aleatoriamente que freqüentemente excedem $500 \mathrm{~m}^{3} \cdot \mathrm{s}^{-1}$, e muitas vezes mais de 1000 $\mathrm{m}^{3} \cdot \mathrm{s}^{-1}$ (Schettini, 2002). O estuário do Rio Itajaí-Açu extende-se até a cidade de Blumenau $(\sim 50 \mathrm{~km}$ a montante da foz), onde observa-se o limite da intrusão da onda de maré. A intrusão de água salgada é variável em função da descarga fluvial, e pode chegar até o município de Ilhota, a mais de 30 $\mathrm{km}$ da desembocadura. Durante períodos de descarga moderada para alta, a concentração de MPS trazido pelo rio aumenta significativamente, e a maior parte é liberada diretamente na zona costeira formando uma pluma fluvial (Schettini, 2002).

\section{EXPERIMENTO 1: PADRÕES DE TRANSPORTE AO LARGO DO ESTUÁRIO DO RIO ITAJAÍ-AÇÚ}

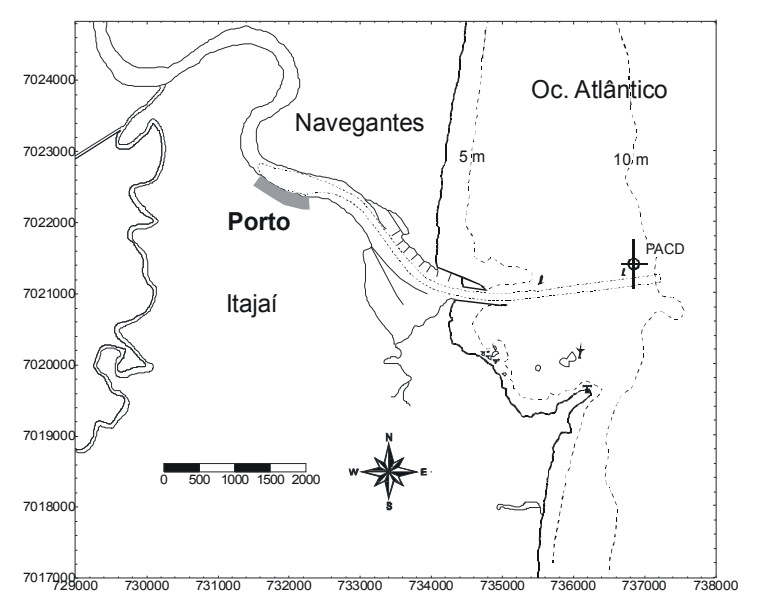

Figura 1 - Localização do fundeio do PACD $\phi$.

Um PACD foi fundeado ao largo do estuário do Rio Itajaí-açú durante o período de 13 de janeiro a 18 de março de 2003, aproximadamente na isóbata de 10 metros (Figura 1). Foi utilizado um PACD da marca Nortek ${ }^{T M}$ modelo Aquadopp Profiler $^{\circledR}$ com freqüência de trabalho de $1 \mathrm{MHz}$ e com sensor de pressão. O PACD foi programado para fazer medições de correntes em células de um metro, a cada hora perfazendo médias de três minutos numa freqüência de amostragem de $2 \mathrm{~Hz}$. O instrumento tem a cabeça de sensores orientada a 90 graus do corpo, possibilitando ficar o mais próximo do fundo possível, e assim ter a primeira célula de medição de corrente localizada aproximadamente a $1 \mathrm{~m}$ acima do fundo.

\section{Regime de Correntes}

Apesar da grande variabilidade temporal e vertical dos dados obtidos com o fundeio do PACD, com diferentes graus de influência de fatores determinantes como a maré, ventos e descarga fluvial, foi possível verificar os padrões gerais das correntes, apresentados na forma de diagramas de distribuição polar (Figura 2). Estes diagramas representam a distribuição de ocorrência de 1532 horas amostradas, onde o nível de cinza indica a concentração de pontos dentro de um intervalo de intensidade $\mathrm{e}$ direção de velocidade.

Foram feitos diagramas a cada metro na coluna d'água a partir de 1 metro acima do fundo até 8 metros acima do fundo, numa coluna d'água de aproximadamente 10 metros. Devido às oscilações de maré e ondas, a camada de 8 metros acima do fundo encontra-se no limite das observações por causa dos efeitos da superfície.

Foi verificado um padrão similar de correntes para as camadas inferiores da coluna d'água, de 1 a 7 metros acima do fundo. Nestas camadas inferiores verifica-se as correntes predominando no sentido norte-noroeste, enquanto que as velocidades aumentam quanto mais próximo da superfície for a camada. Na camada de 8 metros acima do fundo os efeitos da dispersão da pluma estuarina ficam evidentes, com a dispersão do diagrama para leste, alcançando nesta região as velocidades mais intensas, superiores a $0,4 \mathrm{~m} \cdot \mathrm{s}^{-1}$. Estes resultados do regime de correntes corroboram observações anteriores (Schettini, 2002), indicando que a camada de dispersão da pluma estuarina para norte-nordeste, está restrita à camada superficial, entre 1 e 2 metros abaixo da superfície. A componente residual para oeste observada nos diagramas de distribuição polar é uma feição esperada como mecanismo de compensação de volume retirado pelo processo de intrusionamento de massa na interface da pluma estuarina com a água costeira. Esta contra-corrente nas camadas mais profundas, com componente residual para oeste, pode induzir a ressurgência localizada de ACAS (Água Central do Atlântico Sul), caso esta esteja presente nas camadas de fundo. 


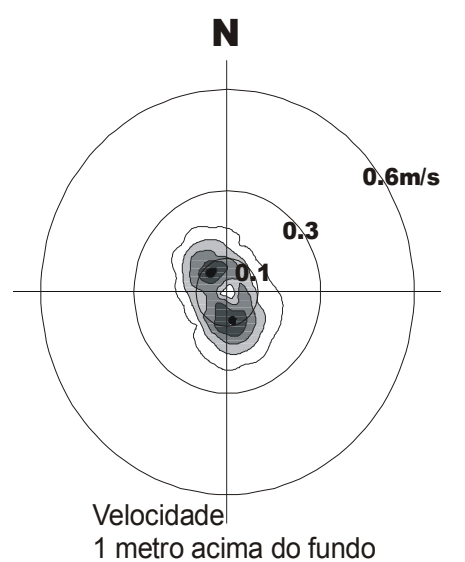

1 metro acima do fundo

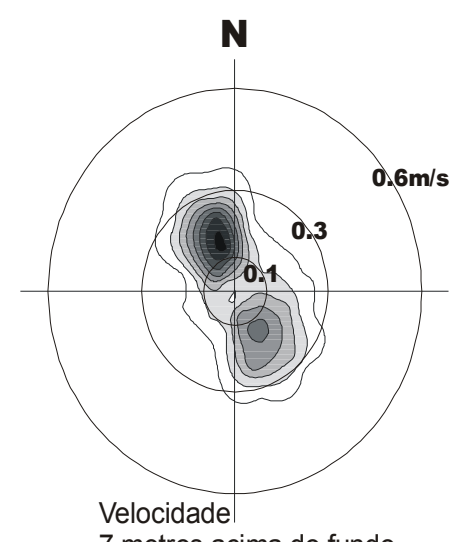

7 metros acima do fundo

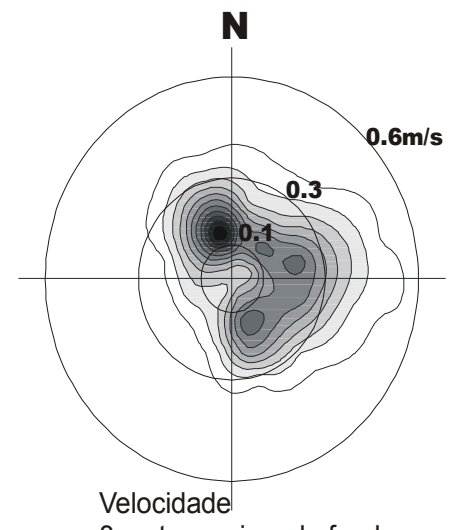

8 metros acima do fundo

Figura 2 - Diagramas de distribuição polar das correntes a 1, 7 e 8 metros acima do fundo ao largo de Itajaí durante o experimento, onde se verificam as intensidades, direções e freqüência de ocorrência das correntes em níveis de cinza.

\section{Transporte do MPS}

Informações sobre a concentração do MPS na água foram obtidas através da conversão do Retro Espalhamento Acústico (REA) coletado pelo PACD através dos procedimentos detalhados em Zaleski e Schettini (submetido). As informações de REA foram convertidas em concentração de MPS a partir das equações primeiramente convertendo o sinal acústico em turbidez:

$$
R E O=148,24-7,61 R E A+0,10 R E A^{2}
$$

Onde REA é a amplitude do sinal acústico corrigida em dB, e REO é a turbidez em FTU. A relação da concentração de MPS, dado em mg. $\mathrm{l}^{-1}$, em função da turbidez é fornecida pela equação

$$
M P S=3,24+2,38 R E O
$$

A partir das informações de velocidade e MPS, ambas obtidas pelo PACD, foi possível avaliar o transporte do MPS ao largo de Itajaí. Para tal foi realizada o produto simples dos valores de velocida- de, em m.s ${ }^{-1}$, pelos valores de MPS convertidos para $\mathrm{kg} \cdot \mathrm{m}^{-3} \mathrm{em}$ cada estrato da coluna de água.

A Figura 3 apresenta, em forma de diagramas polares a direção, intensidade e freqüência de ocorrência do transporte do MPS ao largo de Itajaí sintetizando todo o período monitorado. Os diagramas polares apresentam o transporte nos níveis 1, 3 e 7 metros acima do fundo. A interpretação aprofundada destes resultados está ale do escopo do presente trabalho, mas já permite a um nível elementar verificar que em todos os níveis a direção predominante é para norte-noroeste, e intensidades máximas que vão de $0,01 \mathrm{~kg} \cdot \mathrm{m}^{-2} \cdot \mathrm{s}^{-1}$ a $1 \mathrm{~m}$ acima do fundo, aumentando de intensidade nos níveis mais superiores da coluna de água, onde se verifica um transporte de $0,025 \mathrm{~kg} \cdot \mathrm{m}^{-2} \cdot \mathrm{s}^{-1}$ aos $7 \mathrm{~m}$ acima do fundo. Este aumento deve-se ao incremento das velocidades somadas ao aumento das concentrações de MPS nos níveis mais superiores da coluna d'água.

Devido à proximidade com a superfície, a camada de 8 metros acima do fundo não pode ser utilizada para se estimar a concentração do MPS através deste método. Camadas superficiais, devido à turbulência gerada pelo vento e ondas, possuem uma grande concentração de bolhas de ar, o que compromete a conversão do sinal acústico em concentração do MPS, visto que bolhas de ar também refletem o sinal acústico. 


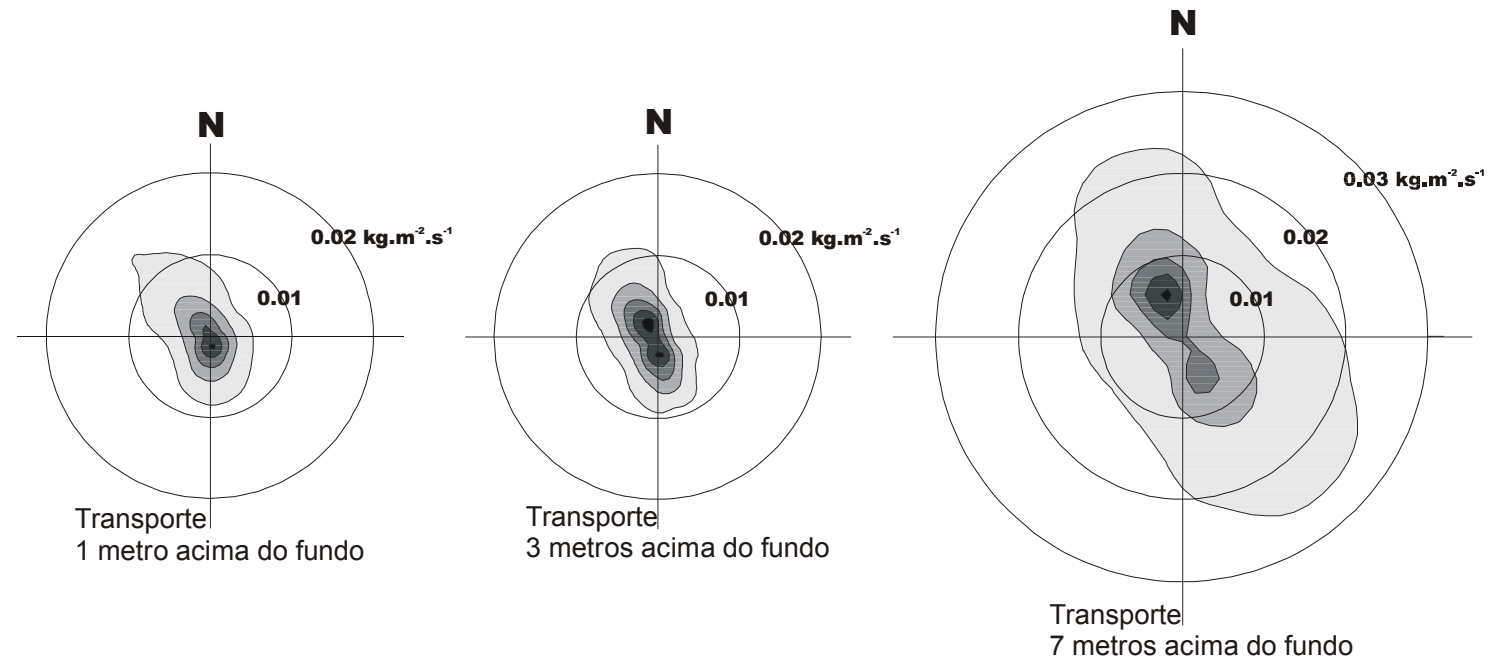

Figura 3 - Diagramas polares do transporte de MPS em 1, 3 e 7 metros acima do fundo.

Os níveis de cinza correspondem à freqüência de ocorrência do transporte.

\section{EXPERIMENTO 2: AVALIAÇÃO DA PLUMA DE SEDIMENTOS GERADA POR UMA DRAGA DE EXTRAÇÃO DE AREIA}

Ao longo do Rio Itajaí-açú existe um grande número de empresas de extração de areia. Estas empresas extraem areia do rio por meio de dragas, que retiram a areia do fundo e a armazenam em um tanque que ocupa quase todo o convés da draga. Estes tanques recebem o fluxo de areia e água retirados do leito do rio e, por densidade, a areia é decantada e armazenada enquanto a água volta para o rio. Porém esta água que volta para o rio carrega consigo uma grande concentração de sedimentos em suspensão, o que gera na área de dragagem uma pluma sedimentar.

Durante a operação de uma destas operava no Rio Itajaí-açú foi realizado um perfil longitudinal de cerca de 200 metros em direção a draga com um PACD montado na embarcação. O PACD utilizado neste caso foi do modelo $A D P$ da marca Sontek ${ }^{T M}$ com freqüência de trabalho de $1,5 \mathrm{MHz}$ e dispositivo de rastreamento de fundo que permite obter dados de corrente a partir de embarcação (Sontek, 1997). O PACD foi configurado para coletar informações em células de meio metro, estando a primeira célula localizada a 1,5 m abaixo da superfície. As informações foram coletas a partir de médias de 10 segundos a $2 \mathrm{~Hz}$ enquanto a embarcação navegava com uma velocidade constante no canal do rio no sentido contrário ao escoamento. Um receptor de sinal de GPS portátil armazenou a rota percorrida pela embarcação.

A partir da informação de REA fornecida pelo PACD foi possível verificar a condição da pluma sedimentar originada pela draga de extração de areia em operação. A calibração do PACD foi realizada similarmente ao descrito para o PACD da Nortek, também para as condições do estuário do Rio Itajaí-açú e com auxílio de um sensor de REO. A relação entre REA e REO também foi não linear, e representada pela equação:

$R E O=5,5 \cdot 10^{-4} e^{0,15 R E A} \quad\left(r^{2}=0,70\right)$

Após a conversão de REA para REO através da Equação 3, a concentração de MPS foi obtida aplicando-se a Equação 2. O resultado do levantamento ao longo da pluma é mostrado na Figura 4.

$\mathrm{O}$ experimento foi realizado sob condições de maré de quadratura, com um nível médio de maré de $0,8 \mathrm{~m}$, fluxo médio de maré enchente de $340 \mathrm{~m}^{3} \cdot \mathrm{s}^{-1}$ (obtido através do levantamento com a PACD na seção transversal) e velocidade média de $0,35 \mathrm{~m} \cdot \mathrm{s}^{-1}$. Observando a Figura 4, pode-se verificar o efeito de escoamento hiperpicnal onde a pluma gera uma fluxo de densidade para o fundo. No presente caso a extensão horizontal da pluma gerada pela draga foi da ordem de $150 \mathrm{~m}$ a partir do lançamento. 


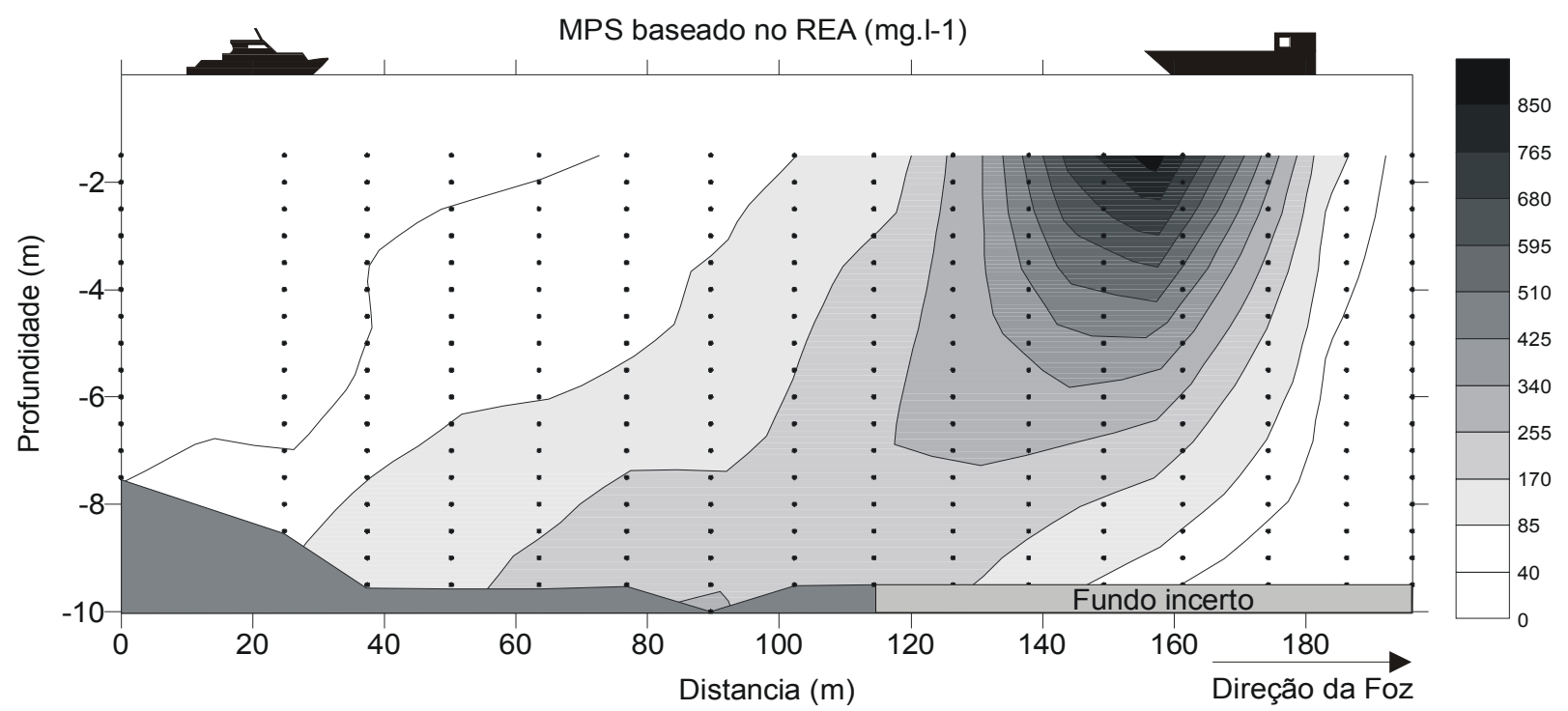

Figura 4 - Pluma sedimentar ocasionada por uma draga de extração de areia no Rio Itajaí-açú a partir do REA obtido pelo PACD 1,5 MHz.

Este experimento demonstrou uma limitação deste método de monitorar o MPS. Observando a Figura 4, verifica-se que nas áreas de maior concentração da pluma sedimentar próximo ao lançamento, onde a concentração estimada de MPS foi maior do que $600 \mathrm{mg} \cdot \mathrm{l}^{-1}$ o PACD perdeu a informação de fundo. Uma possível solução para esta limitação poderia ser o emprego de uma eco-sonda, com uma freqüência de trabalho que consiga penetrar a pluma sedimentar

\section{EXPERIMENTO 3: DISTRIBUIÇÃO DO MPS NO ESTUÁRIO DO RIO ITAJAÍ-AÇÚ SOB CONDIÇÕES DE ALTA DESCARGA DE SÓLIDOS EM SUSPENSÃO}

Uma campanha de campo foi realizada no dia 12 de maio de 2004 com o objetivo de avaliar a calibração do PACD ADP 1,5 MHz em condição de alta descarga fluvial. Similarmente ao descrito para o experimento 2, o PACD foi operado a partir de uma embarcação conectado a um computador portátil. O instrumento foi configurado para coletar informações em células de $0,5 \mathrm{~m}$, fazendo médias de 10 segundos a $2 \mathrm{~Hz}$. Dados foram coletados em intervalos de 1,5 Km a partir da desembocadura até $14 \mathrm{Km}$ para montante. Em cada estação o PACD registrou informações por pelo menos um minuto com o barco posicionado aproximadamente no centro do canal, sendo que a primeira célula de medição posicionada a $1,5 \mathrm{~m}$ abaixo da superfície. Simultanea- mente à aquisição de dados com o PACD, era realizado um perfil da coluna de água para obtenção de dados de REO. Estes foram obtidos com um turbidímetro de REO acoplado a uma sonda CTD modelo $S D 204$ da marca $S A I V / A S^{T M}$, configurada para coletar informações a cada segundo. Posteriormente, em ambiente MatLab, as informações coletadas pela sonda CTD foram convertidas de intervalos de tempo para intervalos de profundidade de 0,5 metro através da pressão.

Através das calibrações realizadas anteriormente do Turbidímetro de REO (Equação 2) e do PACD (Equação 3) foi gerado um perfil verticallongitudinal da distribuição do MPS ao longo do estuário do Rio Itajaí-açú com ambos os instrumentos (Figura 5).

Os resultados de distribuição de concentração de MPS obtido a partir do turbidímetro de REO e a partir do REA do PACD foram bastante diferentes um do outro. Na porção do estuário até $4 \mathrm{Km}$ a montante da foz os resultados são similares, indicando valores de MPS da ordem de 20-40 mg. $\mathrm{l}^{-1} \mathrm{e}$ aumentando para o fundo. Contudo, os resultados obtidos através de REO indicam o aumento da concentração na camada de superfície para montante, enquanto que o mesmo não ocorre com a distribuição obtida através de REA. Na camada de fundo as variações concordam. Esta diferença de resultado é bastante diferente dos resultados apresentados por Zaleski e Schettini (submetido), onde a concordância é bastante boa entre as distribuições obtidas pelos diferentes métodos. 
A Utilização de Perfiladores Acústicos de Corrente por Efeito Döppler na determinação do Material Particulado em Suspensão na Água: Aplicações
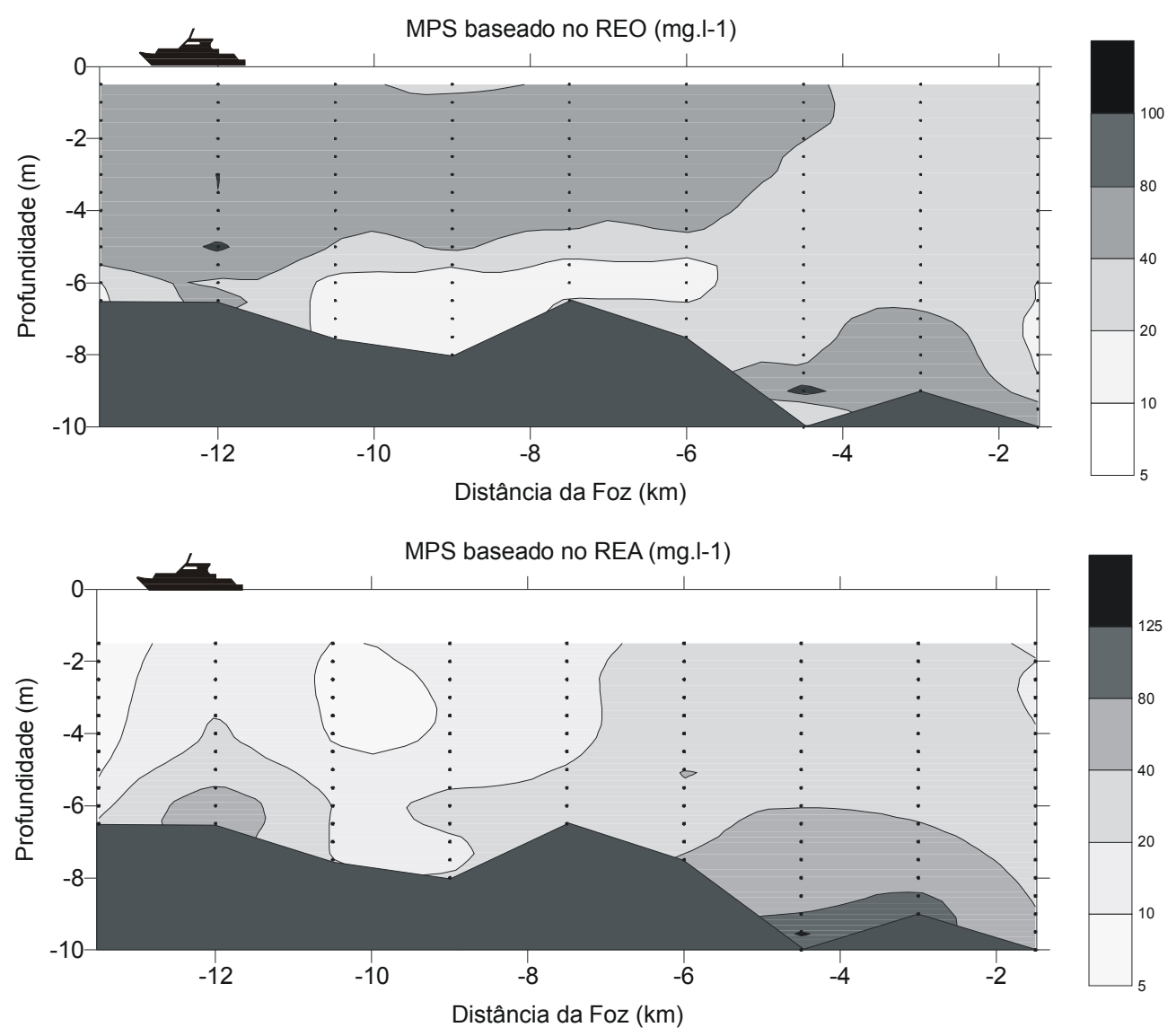

Figura 5 - Perfil vertical-longitudinal da distribuição do MPS ao longo do estuário do Rio Itajaí-açú a partir do TREO (acima) e do PACD (abaixo).

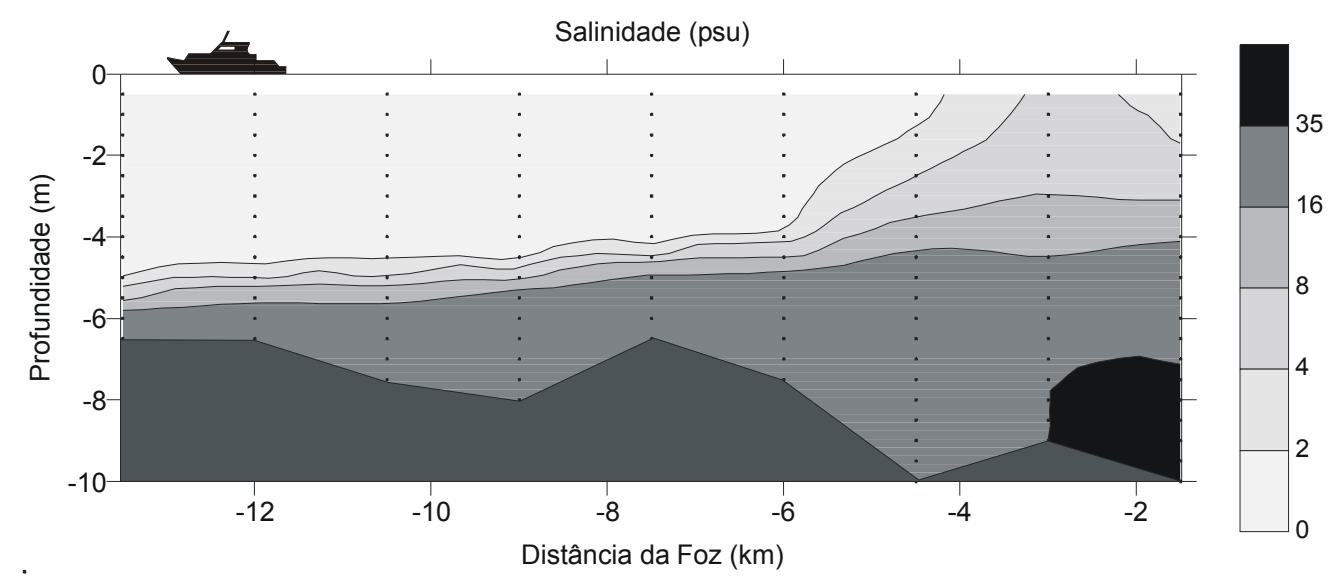

Figura 6 - Perfil vertical-longitudinal da distribuição de salinidade ao longo do estuário do Rio Itajaí-açú.

A distribuição vertical e longitudinal da salinidade durante a campanha é apresentada na Figura 6. Observa-se que a condição do estuário estava altamente estratificada, principalmente para montante de $6 \mathrm{Km}$ da foz, quando a camada de superfície apresenta salinidade inferior à 2, ocorrendo uma 
forte haloclina, e salinidade acima de 16 próximo do fundo. Este gradiente acentuado de salinidade, com água e característica fluvial sobre água salobra, possivelmente acarreta uma diferenciação nas populações de partículas em suspensão. O MPS fluvial caracteriza-se pela dominância de sedimentos inorgânicos argilosos desagregados ou formando flocos pequenos e facilmente destruídos pela turbulência de dimensões da ordem de poucas dezenas de micrômetros. Quando a água fluvial mistura-se com a água marinha nos estuários, em função da provisão de eletrólitos e matéria orgânica dissolvida, o MPS passa a formar flocos maiores e mais resistentes, chegando a tamanhos bem maiores que $100 \mathrm{~m}$ (Eisma, 1986).

O PACD foi previamente calibrado para condições salobras e salinas, onde mesmo que exista uma variação no tamanho do MPS, este estará preferencialmente no formato de flocos. Desta forma, a discrepância observada pode ser explicada através das diferentes sensibilidades dos sensores aos diferentes tamanhos de partículas em suspensão (Nortek, 2001). Os sistemas óticos são menos sensíveis às variações no tamanho de partículas, enquanto que o PACD estaria sensível apenas às partículas de tamanhos maiores (Gartner, 2002).

\section{CONSIDERAÇÕES FINAIS}

Foram realizados três experimentos onde se buscou verificar as vantagens e desvantagens de se estimar a concentração do MPS na água através das informações de REA coletadas por PACDs convencionais

Experimento 1: a limitação verificada neste experimento ao largo do estuário do Rio Itajaí-açú foi a impossibilidade de utilizar o PACD em estudos da dispersão da pluma fluvial. A pluma está restrita aos primeiros decímetros e metros da superfície, onde em função da presença de ondas que gera incerteza da camada superficial, e bolhas, não é possível obter estimativas confiáveis da concentração do MPS. No entanto, se o foco não é avaliar os processos na pluma, mas o transporte sedimentar costeiro em geral, a aplicação do PACD mostrou-se bastante satisfatória.

Experimento 2: as concentrações de MPS bastante altas geradas pelo extravasamento da draga impossibilitou o instrumento utilizado de obter o rastreamento de fundo, impedindo assim de estimar a velocidade de corrente e a profundidade. A velocidade pode ser estimada com o uso de um sistema de posicionamento global por satélites com corre- ção diferencial. E a profundidade pode ser obtida com uma ecosonda. Assim, uma incorporado estes itens, o PACD torna-se uma ferramenta ideal para este tipo de estudo, dada a compatibilidade das escalas de tempo envolvidas (segundos/minutos).

Experimento 3: neste experimento com alta estratificação da coluna de água verificou-se a limitação do PACD em visualizar partículas mais finas em suspensão associadas com a água fluvial. O instrumento utilizado foi calibrado em condições salobras e salinas, e talvez uma calibração para condições fluviais corrija esta deficiência, ao menos parcialmente. Contudo, ainda se desconhece a variação do tamanho do MPS no estuário do rio Itajaí-Açu, e somente um estudo sobre isto poderá fornecer uma melhor idéia de como contornar este problema.

Apesar das limitações constatadas, o uso de PACDs no estudo e monitoração do MPS em estuários e águas costeiras é bastante promissor, principalmente no que diz respeito a resolução espacial e temporal de coleta de dados.

\section{REFERÊNCIAS}

Gartner, J. W. 2002. Estimation of suspended solids concentrations based on acoustic backscatter intensity: Theoretical background. Turbidity and Others Surrogates Workshop, april30 - may2nd , 2002, Reno, NV.

Eisma, D. 1986 Flocculation and de-flocculation of suspended matter in estuaries. Netherlands Journal of Sea Research, 20(1/3):183-199.

Nortek Technical Notes, 2001. Monitoring Sediment Concentration with Acoustic Backscattering Instruments. Nortek technical note No. 003. 5p.

Schettini, C. A. F., 2002. Caracterização física do estuário do rio Itajaí-Açu. Revista Brasileira de Recursos Hídricos, 7(1), pp. 123-142.

Sontek Technical Notes, 1997. Acoustic Doppler Profiler (ADP) principles of operation. Sontek Inc., San Diego, CA, USA, 12p.

Zaleski, A. R., Schettini, C. A. F., Submetido. Procedimentos para Calibração de Perfiladores Acústicos de Corrente por efeito Doppler na Determinação da Concentração de Material Particulado em Suspensão na Água. Revista Brasileira de Recursos Hídricos. 
A Utilização de Perfiladores Acústicos de Corrente por Efeito Döppler na determinação do Material Particulado em Suspensão na Água: Aplicações

\section{The Use Of Acoustic Doppler Current Profilers To Determine Suspended Particulate Matter In Water}

\section{ABSTRACT}

Three experiments showed the performance of two models of standard ADCP's for Suspended Particulate Matter (SPM) measurements. In the first experiment an ADCP was deployed for two months offshore in the Itajai-açu river estuary, at a depth of Approximately 10 meters. The data allowed verifying the currents and SPM transport patterns. The second experiment monitored a sedimentary plume caused by a dredge. Using an ADCP with the "bottom tracking" device, that allowed shipborn-mounted use of the instrument. a 200-meter profile was made in the direction of the dredge while it was operating. From the acoustic information acquired by the ADCP it was possible to see the sedimentary plume caused by the dredge and estimate its SPM concentration. In this experiment a limitation of this method could be seen. when there was a high concentration of SPM , the ADCP could not obtain bottom information. In the last experiment the distribution of the SPM in the estuary under high discharge of suspended solids was verified. Using an ADCP and an Optical Backscattering System, vertical-longitudinal profiles of the estuary were made simultaneously to compare the measurements. This experiment showed another limitation of this method, particle size and frequency limitations. The ADCP used could not view fine particles present in this estuary. the fine particles could only be seen by Optical sensor.

Key-words: Estuary, Sediments, ADCP. 